\title{
THERMOPLASTIC MANDIBULAR TOOTH SUPPORTED OVERDENTURES VERSUS ACRYLIC ONE (MAXILLARY TISSUE CHANGES)
}

\author{
Mohamed Aboshama * and Asem Mohamed Kamel **
}

\begin{abstract}
Objectives: The work was to determine the maxillary tissue changes under acrylic and flexible lower tooth supported overdentures.
\end{abstract}

Methods: The study was accomplished on 20 patients; the selected cases were upper completely edentulous and lower tooth supported one. lower overdenture supported with canines bilaterally. The cases randomly split into two groups: Group I; ten patients wear acrylic complete upper denture and acrylic mandibular tooth supported overdenture Group II; ten patients wear flexible complete upper denture and flexible lower tooth supported overdenture.

Clinical tests were performed by measuring the soft tissue thickness of superimpose the anterior upper ridge at 2 dots $1 \mathrm{~cm}$ and $2 \mathrm{~cm}$ on each hand to the midline at time of prosthesis delivery and at 12 months. Also, radiographic evaluations of upper edentulous area estimated at time of prosthesis delivery and at 12 months.

Results: there was non-significant increase in upper mucosa thickness in both groups at both points of measurements. Also, both groups showed radiographic bony changes in maxillary ridge. There was significant increase in maxillary bony changes in Group I in compare to Group II.

Conclusion: it was concluded that there was slight increase in the thickness of soft tissue above the anterior upper ridge in each sequence. More bone resorption allover region of maxilla was observed in Group I, but there was slight decrease in Group II more than Group I.

KEYWORD: Tooth supported overdentures, thermoplastic and acrylic dentures, soft tissue Improvements in the upper edentulous area, upper edentulous area radiographic evaluations

\footnotetext{
*Lecturer of Removable Prosthodontic Department. Faculty of Dentistry, Al-Azhar University (Assiut), Assiut Branch. Egypt.

** Lecturer of Oral medicine, Periodontology, Diagnosis and Radiology Department. Faculty of Dentistry, Al-Azhar University (Assiut), Assiut Branch. Egypt.
} 


\section{INTRODUCTION}

Defined as a weaken toothlessness situation, affect oral validity, ${ }^{1}$ it was considered likely to be settled on the elderly patient. ${ }^{2}$

Kelly intellect that the early bone loss is to the key to the other changes in the anterior maxilla and celebrated that as of the premaxilla resorption progressed, further tissue damage and denture instability are proceeding proportionately. ${ }^{3}$

Restoration of lower jaw toothlessness accomplished over different style of restorative handling such complete dentures, fixed prostheses, removable hybrid prosthesis. ${ }^{4}$

Preservation of the remaining tissues is the main purpose of removable prosthodontics treatment. ${ }^{5}$

Overdenture can provide, as premium gage for cases with roughly hopeless or diminutive dentition controlled for total extraction, because overdenture is interested in persistent alveolar bone maintenance of the implants / supported teeth/root components. Overdenture has Also preserved the periodontal sensory technique which indexes and observe gnathodynamic tasks, which will advance gnathodynamic psychology and functions of individual's, as it maintained the proprioceptive impulses . ${ }^{6}$

Tooth-supported overdenture use is a general form of treatment , ${ }^{7}$ the result from denture pressure on a residual ridge is bone resorption wear. Maintaining the abutment tooth beneath removable prosthesis as opposed a compression implementation ${ }^{8}$

The existence of undercuts either soft or osseous tissue, tangles the therapy schedule ${ }^{9}$ In this clinical situation there may be a problem in the placement of dentures, bulbous labial cortical plates with heavy labial undercut may affect appearance of the dentures. ${ }^{10}$

Specific prosthetic specialist handling of the undercuts is done by finishing the denture to the entire vestibule peak and by blocking out undercut on the cast. Substitution, the elevation of the periphery of the dentures may be diminutive to the top of undercut. Also applicable to denture base adjustment with reduced border seal. ${ }^{11}$

Except mechanical properties, poly methyl methacrylate (PMMA) has the key characteristic main for ideal denture- base material. PMMA is substance of preference for denture bases and for denture relining, obturators, orthodontic appliance, provisional bridge, stents. Properties of the denture base substance include, marked appearance, fully marked manufacturing, fabrication techniques, remedial facility, simple ready and minimal price.$^{12}$

As recent developments in material science, Thermoelastic dentures have resulted in various edentulous circumstances being handled as a option.

Over the conventional hard denturebases it has offered many features. Existence of elastic denture, the base of denture is completely installed in undercut region. the magnitude of desired modification at appointment of denture delivery will be greatly reduced and that decrease after wearing prosthesis claims stimulated the impact. The presence of flexible substances existence as solid, malleable and soft can be synthetic thin in thickness and are lighter in composition weight for conventional dentures.$^{13}$

A substitutional nature of overlay denture in the ideal flange thickness and height can be achieved by using flexible denture base materials. It is thermoplastic material based on nylon that retains beauty and does not lose function; Soft dentures are a luxury alternative to conventional hard-fitted dentures. Conventionally relining dentures with a soft base increases comfort at the cost of efficiency in chewing. To offset chewing performance disturbance, denture wearers will use adhesive dentures that create their own troubles. This statement is intended to attend a patient's handling of Flexible Denture. ${ }^{14}$ 
Metal-free dentures (flexible dentures) are commonly known as flexible resin. Flexible denture offers excellent appearance, immovability, enhanced cases resting because flexible material and minimal elasticity modulus require minimal development time and expense. ${ }^{15}$

As alternative to traditional hard-fitted dentures 16, Thermoplastic dentures are inserted. Thermoplastic resins may generally be classified as polycarbonates in thermoplastic form. Thermoplastic acetal, thermoplastic acrylic, and thermoplastic nylon. ${ }^{17,18}$ The mechanical characteristics of thermoplastic denture base were elaborate in comparison with the traditional heat-cured PMMA and fiber reinforced PMMA denture base materials. The base material thermoplastic denture had the highest transverse strength and no fracture was noted.$^{19}$

This research was carried out to assess the radiographic influence of acrylic and flexible denture base material on the sporting structures in the edentulous maxillary area. Scaling changes in bone height in maxillary extension area.

\section{METHODS}

Research in the Removable prosthodontics was completed, twenty female cases were the entrants to this research.

The patients age ranged from between 45 and 60 years. The basic inclusion criteria were followed with perfect oral hygiene measures and cases with adequate inter arch distance. Residual teeth Patients with bruxism, ultimate systemic disease, radiationtreated patients and patients with oral hygiene inferior were excluded. The patients agreed to an informed written consent.

Case's selected was based primarily on panoramic view radiography and clinical inspections. The Cases had ended a one- year follow-up interval.

\section{Construction of an overdenture}

Preliminary impression was taken by alginate impression material, this impression was casted, while individual trays were made of auto polymerized acrylic resin. Peripheral tracing with Greenstick compound was performed for both jaw.

\section{Preparation for the Abutment}

Treatment program included bilateral arc periodontal therapy and endodontic therapy for the canine teeth. Canine Abutment as a collar - form contour hemi ball-shaped supra gingivally and rounded in all dimensions was reduced by about two-three millimeters. Figure $\mathbf{1 A}$ covered the abutment with metallic coy.

Following abutment preparation, the secondary impression was made with medium form rubber base impression material. Final casts were poured, and the occlusal blocks were manufactured after setting it; using face-bow recording, jaw relationship registration and relocation to the semi-adjustable articulator. The teeth were Set up and waxed and attempted intraorally for speech, vertical and horizontal relationship and ultimately appearance was done.

Vertical distance verification of and lateral contact checking were done. The agreement of the case was achieved, and the polymerization of the final denture was made in acrylic heat-cure resin.

Overdentures were delivered and prescriptions were awarded for post insertion.

For first group, each patient had upper complete denture and lower tooth supported overdenture. Figure 1B.

For the Second group prothesis was fabricated from thermoplastic material. Similar procedures as heat cure based on acrylic resin denture but thermoplastic resin material is used to produce of flexible denture bases. 
Particular kind of flasks were used with complete denture base materials in the thermo press, during flasking through injection channels between the flask and the model injection opening. As conventional steps, the dentures separated from the final cast and terminated and polished.

After fabrication of flexible overdentures and delivered to group II Figure 1C, clinical assessment were performed by medially scaling the thickness of the soft tissue above the anterior upper ridge at 2 positions $1 \mathrm{~cm}$ and $2 \mathrm{~cm}$ from both sides by using a piercing probe with rubber stopper Figure 1D. at time of delivery of prosthesis and at 12 months.

The scale was collected, and the average was studied and analyzed through follow- up at delivery and at 12 months to estimate the effect on the mucosa of antagonistic upper bony ridge under complete denture of two materials of mandibular tooth-supported overdentures.

\section{Cone beam CT assessment of radiographic data}

Radiographic tests of the upper edentulous area were also conducted, and the amount of bone resorption was measured at time of delivery of prosthesis and at 12 months.

Planmeca Romexis ${ }^{\circledR}$ (Planmeca, Helsinki, Finland) had CBCT images at $90 \mathrm{kVp}, 6 \mathrm{mAs}$, 20 -second acquisition time, and efficient radiation dosage the patient exposed was $101.5 \mu \mathrm{Sv}$ for the patient exposed.

There were two cycles of CBCT radiographs occupied, the first prior to treatment and the second one-year after treatment. Even, one radiographic technologist and using the same CBCT system and parameters took those images.

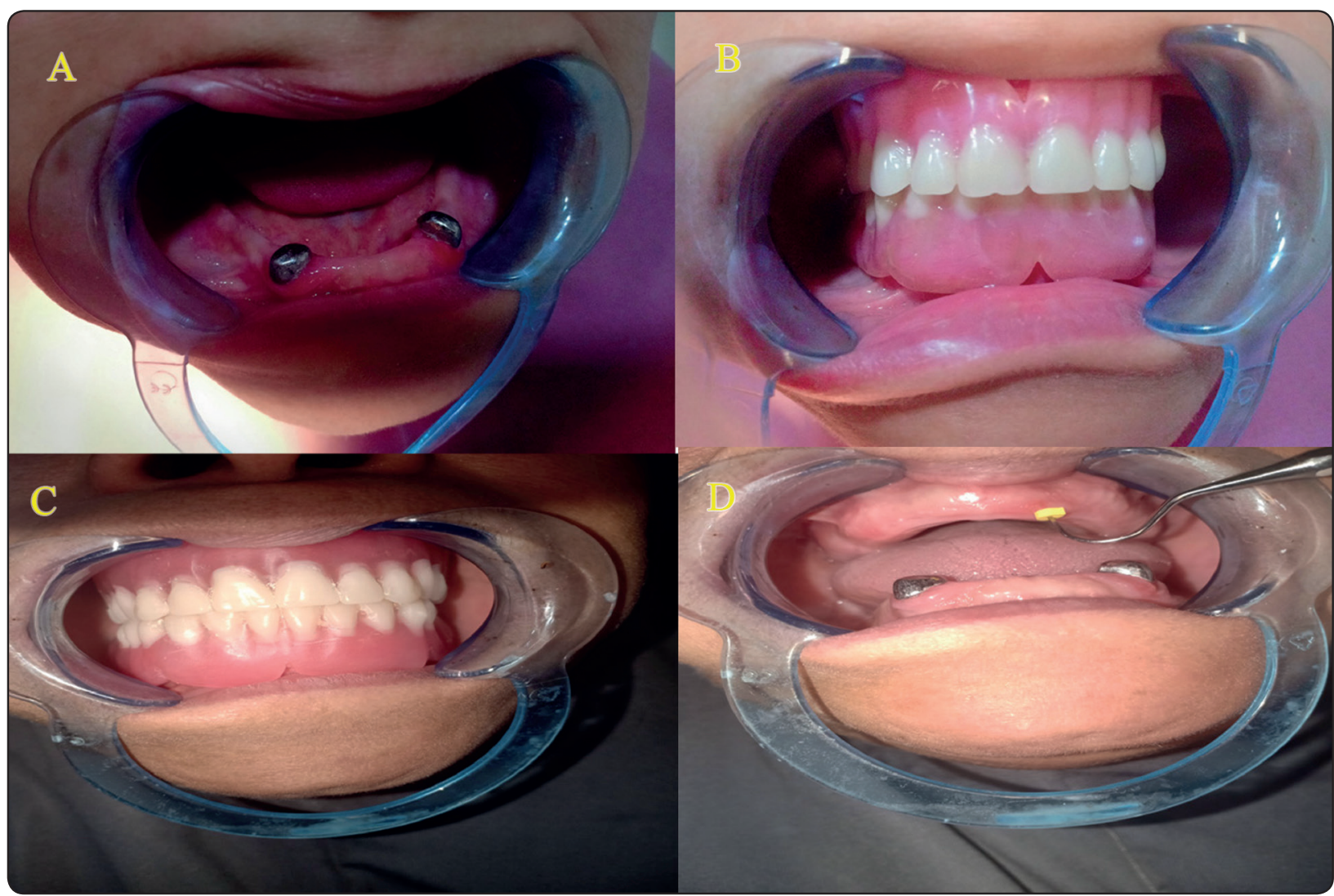

Fig. (1) Figure 1. A The overdenture abutment was covered by metallic coy. B. acrylic overdenture. C. Flexible overdenture delivered to group II. D. scaling the thickness of the soft tissue by utilizing a piercing probe. 


\section{Measuring of quantality of the maxillary bone}

Measurements of bone height and width at midline, canine positions first molar and tuberosity were recorded on both sides.

\section{- Bone height}

From an axial point of view, horizontal plane was checked to thread through inferior zygomatic process boundaries. A line drawn from the vertical ridge crest to line symbolizing the horizontal plan passes through the lower border of zygomatic process in sagittal view. Length of this line in different selected points was studied as bone height.

\section{Figure 2A}

\section{- Bone width}

From the sagittal point of view, five mm of the horizontal plan under the plane thread was checked through the lower surface of zygomatic arch. The thickness of alveolar ridge at axial view. A line to buccal bone to lingual bone was drawn vertically and the length of this line was studied and registered.

\section{Figure 2B.}

All data was gathered, tabulated, and statistically analyzed.

\section{RESULTS}

\section{Result of Clinical Evaluation}

Thickness of Soft tissue means changes above the anterior maxillary ridge $(1 \mathrm{~cm}$ and $2 \mathrm{cmm}$ to midline) are presented in Group I and II. Among both categories, the means of soft tissue thickness overlying maxillary ridge were usually higher than that during insertion at both points during follow up ( $1 \mathrm{~cm}$ and $2 \mathrm{~cm}$ to midline) Figure 3 . Was statistically insignificant for Those changes.

TABLE (1) provides an example of unpaired t test comparing clinical upper Soft tissue thickness (increasing) at two sites over a year of wearing in the overdentures in both classes. .

\begin{tabular}{|l|l|l|}
\hline Site & $\mathbf{t}$ & $\mathbf{p}$ \\
\hline $1 \quad$ cm to midline & 3.01 & $0.01 * *$ \\
\hline $2 \quad \mathrm{~cm}$ to midline & 5.58 & $0.00 * *$ \\
\hline
\end{tabular}

Means of changes in the thickness of the soft tissue overlying the upper anterior ridge $(1 \mathrm{~cm}$ and $2 \mathrm{~cm}$ to midline) for Group II; were generally higher than in Group I through the follow up period. Those differences However, have not been statistically significant.
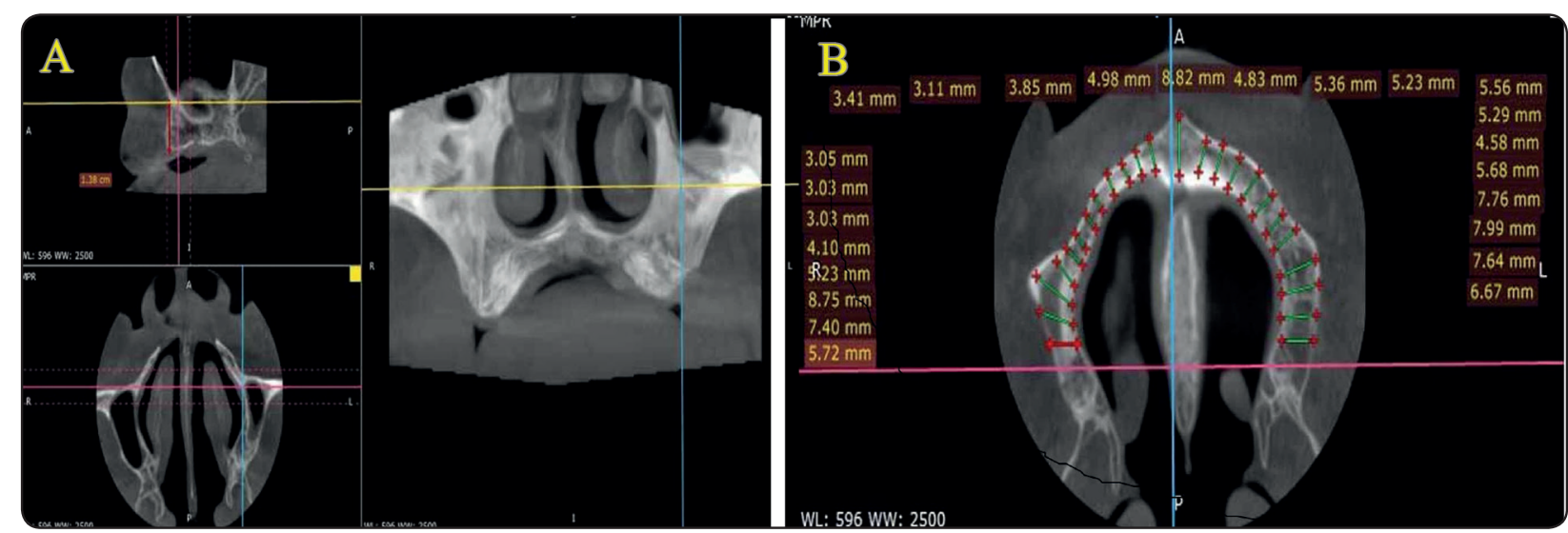

Fig. (2) A.sagittal plane showing radiographic maxillary height. B. Axial plane showing radiographic maxillary width. 


\section{Results of Radiographic Assessment:}

The results of Radiographic Evaluation were summarized in table $(\mathbf{2 , 3})$ and figure $(\mathbf{4 , 5})$ for each group.

\section{The Maxillary Radiographic height changes}

Comparison of Maxillary height changes using unpaired t test between two groups:

TABLE (2): Illustration of unpaired t test Comparison of radiographic changes in maxillary height (resorption) between the two groups at different sites in the maxillary ridge after year of overdentures wearing.

\begin{tabular}{|l|l|l|}
\hline Site & $\mathbf{t}$ & $\mathbf{p}$ \\
\hline Midline & 2.01 & 0.07 \\
\hline $5.0 \mathrm{~cm}$ to midline & 1.29 & 0.22 \\
\hline $1 \quad 1.34$ & 0.21 \\
\hline $1.5 \mathrm{~cm}$ to midline & 0.13 & 0.8 \\
\hline $2 \quad \mathrm{~cm}$ to midline & 0.11 & 0.9 \\
\hline $2.5 \mathrm{~cm}$ to midline & 1.5 & 0.1 \\
\hline $3 \quad \mathrm{~cm}$ to midline & 0.4 & 0.6 \\
\hline $3.5 \mathrm{~cm}$ to midline & 0.7 & 0.4 \\
\hline $4 \quad \mathrm{~cm}$ to midline & 2.8 & $0.02 * *$ \\
\hline $4.5 \mathrm{~cm}$ to midline & 3.2 & $0.01 * *$ \\
\hline $5 \mathrm{~cm}$ to midline & 2.7 & $0.02 * *$ \\
\hline $5.5 \mathrm{~cm}$ to midline & 3.6 & $0.00 * *$ \\
\hline Tuberosity & 3.3 & $0.00^{* *}$ \\
\hline
\end{tabular}

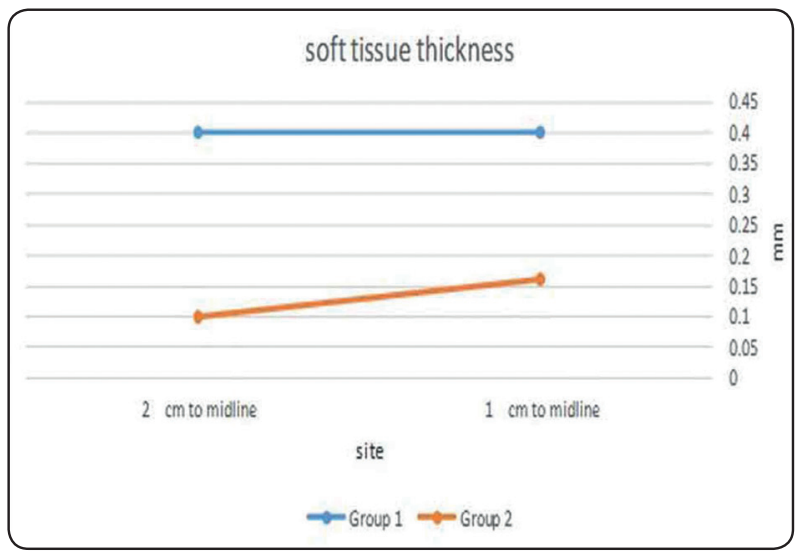

Fig. (3) Line chart showing means of clinical maxillary Soft tissue thickness (increasing) in both groups at two sites over year of wearing prosthesis.
Comparison of changes in Maxillary width between two groups using unpaired test

TABLE (3): Illustration of unpaired t test Comparison of radiographic changes in maxillary width (resorption) between both groups at different sites of maxillary ridge after year of the overdentures wearing.

\begin{tabular}{|l|l|l|}
\hline Site & $\mathbf{t}$ & $\mathbf{p}$ \\
\hline Midline & 0.32 & 0.75 \\
\hline $5.0 \mathrm{~cm}$ to midline & 2.22 & 0.05 \\
\hline $1 \quad \mathrm{~cm}$ to midline & 1.58 & 0.15 \\
\hline $1.5 \mathrm{~cm}$ to midline & 1.68 & 0.13 \\
\hline $2 \quad \mathrm{~cm}$ to midline & 1.55 & 0.15 \\
\hline $2.5 \mathrm{~cm}$ to midline & 1.26 & 0.24 \\
\hline $3 \quad \mathrm{~cm}$ to midline & 1.43 & 0.18 \\
\hline $3.5 \mathrm{~cm}$ to midline & 2.54 & $0.03 * *$ \\
\hline $4 \quad \mathrm{~cm}$ to midline & 2.44 & $0.04 * *$ \\
\hline $4.5 \mathrm{~cm}$ to midline & 2.44 & $0.04 * *$ \\
\hline $5 \mathrm{~cm}$ to midline & 3.72 & $0.00^{* *}$ \\
\hline $5.5 \mathrm{~cm}$ to midline & 3.66 & $0.00^{* *}$ \\
\hline Tuberosity & 5.60 & $0.00^{* *}$ \\
\hline
\end{tabular}

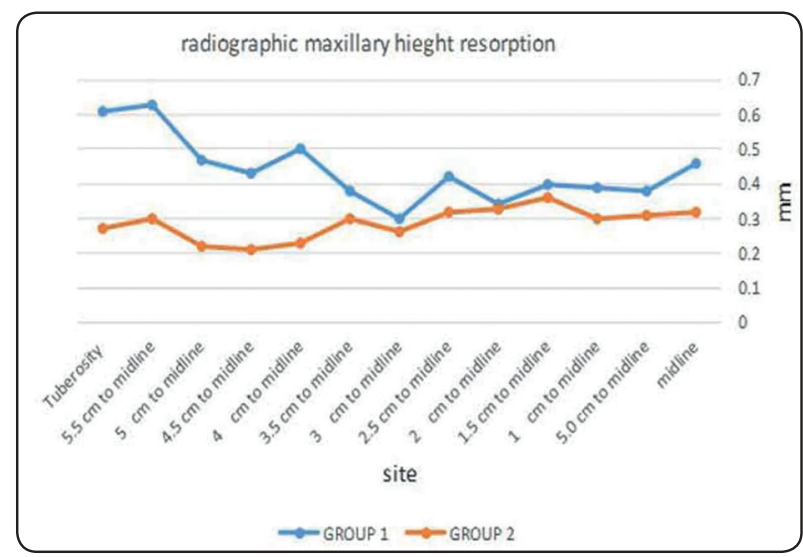

Fig. (4) Line chart representing mean values of maxillary height changes 


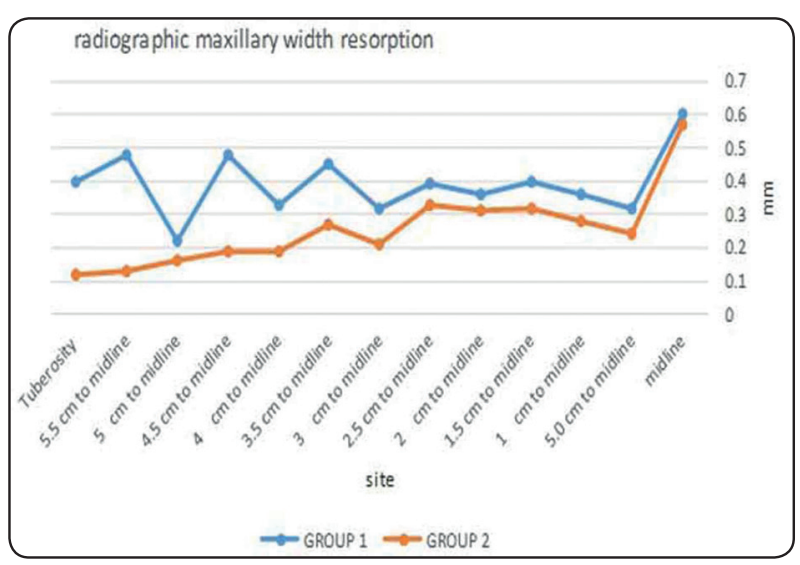

Fig. (5) Line chart representing mean values of maxillary width changes

\section{DISCUSSION}

All selected patients were healthy and free from any systemic disease that may adversely affect the oral cavity condition, improve bone resorption or change the oral ecology and thus affect the finding of this research.

For elderly people with partially or completely edentulous cases, Different forms of treatment may appear, acrylic complete dentures and supported together with teeth, and implant-supported overlay denture are popular fashion therapy. Maintaining teeth of protected by these overlay denture abutments offer efficient restorative handling. ${ }^{20}$

Maintaining enough practical pressure allocation while perfect oral hygiene among the residual ridge and abutment tooth promoting the prediction of that style handling. ${ }^{21}$

Use naturalistic dentition as overdenture abutments (overlay denture) that have become an effective substitute for the removal of residual dentition over the past few years. ${ }^{22}$

The maintenance of supporting teeth as an abutment of overdenture provided effective prosthetic treatment. This method of the therapy is price - efficient, preserves proprioceptive teeth response and decreases alveolar bone resorption altogether. ${ }^{20}$
Lower canines were retained and applied as overlay denture abutments in the tooth-supported overdenture group in order to endodontically handle the lower capsids, have potent roots, and strategic roots exist in the lower arch angle. Additionally, the Preservation of lower capsids has the main interest in alveolar bone conservation, especially in lower anterior part.

Dome shape and reduction of Canine abutments approximately three $\mathrm{mm}$ above the free gingival margin to provide contact mark between denture base and abutment to release lower denture movement which minimizes harmful horizontal pressure influence. ${ }^{23}$

Substitutional to Poly Methyl Methacrylate, another denture base material that is the material thermoplastic resin that can be a beneficial in particular circumstances where higher flexibility, higher impact resistance and flexural fatigue are desired ${ }^{24}$

The anterior part of the maxilla is the lowest part of the maxillary arch to endure pressure as overdenture abutment occurs in the edentulous mandible. ${ }^{25}$

Measurement of marginal alveolar bone levels in integrated and sequential radiographs, and of those variation over time, is considered a serious parameter for estimating the success of prothesis during the research period.

In this analysis the amount of bone loss of maxillary residual ridge over the interval span of this analysis was not found statistically significant in either groups, this may be due to flexible and resilience nature of the material which helps to absorb the occlusal load and minimize the damaging impact on maxillary residual ridge.

Overlay denture minimizes residual ridge resorption and minimizes alveolar bone compression. In situation of overlay denture prosthesis, proprioceptive property is preserved. ${ }^{1}$ 
Although the results offered significant difference between group I and group II, it appears that group II has been slightly better, which can be attributed to the more material elasticity and patient satisfaction in flexible overdenture.

\section{CONCLUSION}

Compared to methyl meth-acrylate dentures the flexible denture is a promising material. Thermoplastic materials considered an alternative to the base material for acrylic resins.

Based on the findings of this study, it was deduced that there was a small increase in the thickness of soft tissue above the upper ridge in both groups. In Group I patients more bone resorption was observed in a whole maxilla region, but in Group II there was a slight decrease more than Group I.

In flexible lower tooth supporting overdentures opposing the upper maxillary edentulous area, there was finally better value than acrylic one.

\section{REFERENCES}

1. Jain S, Rathod A, Singh R, Mistry G. Maxillary toothsupported bar overdenture: A case report. 2019.

2. Patel J, Jablonski RY, Morrow LA. Complete dentures: an update on clinical assessment and management: part 1 . BDJ. 2018; 8:707-14.

3. Abdel-Fattah A, Abdel-Ghany M, El-Mahrouky N, ElSayed S, Al-Mahdy Y. Maxillary Tissue Changes under Complete Dentures Opposing Two Different Mandibular Implant Support Overdentures. Al-Azhar Dental Journal for Girls. 2018; 1:65-77.

4. Taha ER, Elsharkawy RT, Metwaly AF, Fadl AF. Bone Height Changes In Maxillary Arch Opposing Four Implant Retained Mandibular Over Dentures Versus All-On-Four Hybrid Mandibular Prostheses A Prospective Randomized Clinical trial. Egypt Dent J. 2019; 1:205-13.

5. Zidan YSE, Gamal El-Din HM, Kholief DM. Effect of Occlusal Reactive and Thermoplastic Denture Bases on Supporting Structures in Lower Distal Extension Partial Dentures. Al-Azhar Dental Journal for Girls. 2018; 4:359-64.
6. Shah D, Vaishnav K, Matani H, Patel P. Overdenture: conventional to contemporary: a review. J Res Adv Den. 2013; 2:24-30.

7. Shinde GB, Wadkar AP. Overdenture: a way of preventive prosthodontics. Indian Journal of Dental Advancements. $2012 ; 2: 863-8$

8. ShanKaR YR, Srinivas K, Surapaneni H, Reddy SVS Prosthodontic treatment using vital and non vital submerged roots-two case reports. JCDR. 2013; 10:2396.

9. Shamnur SN, Jagadeesh KN, Kalavathi SD, Kashinath KR. Flexible dentures-an alternate for rigid dentures. J Dent Sciences and Research. 2010;1:74-9.

10. Chaturvedi S, Shah M, Ghodpage SL, Kulkarni M, Gill S. Unconventional prong dentures-a case report. International Journal of Dental Clinics. 2013; 1.

11. Chakravarthy Ramasamy AA. Prosthodontic Management of Undercut Tuberosities: A Clinical Report. J Clin Diagn Res. 2011; 8:1692-4.

12. Saeed F, Muhammad N, Khan AS, Sharif F, Rahim A, Ahmad P, et al. Prosthodontics dental materials: From conventional to unconventional. Materials Science and Engineering: C. 2020;106:110167.

13. Dhiman RK, Chowdhury SKR. Midline fractures in single maxillary complete acrylic vs flexible dentures. Med J Armed Forces India. 2009; 2:141-5.

14. Vikhe DM, Saraf V, Gangadhar SA, Bhandari A, Vikhe G, Tambe SD. Flexible denture-A flexible substitute for Rigid Denture. Pravara Medical Review. 2016; 1:30-2.

15. Ahuja S, Jain V, Wicks R, Hollis W. Restoration of a partially edentulous patient with combination partial dentures. BDJ. 2019; 6:407-10

16. Sakr HM, Fayad M. Bite force and oral health impact profile in completely edentulous patients rehabilitated with two different types of denture bases. Tanta Dental Journal. 2017; 4:173.

17. Shah VR, Shah DN, Chauhan CJ, Doshi PJ, Kumar A. Evaluation of flexural strength and color stability of different denture base materials including flexible material after using different denture cleansers. J Indian Prosthodont Soc. 2015; 4:367.

18. Singh K, Aeran H, Kumar N, Gupta N. Flexible thermoplastic denture base materials for aesthetical removable partial denture framework. JCDR. 2013; 10:2372. 
19. Soygun K, Bolayir G, Boztug A. Mechanical and thermal properties of polyamide versus reinforced PMMA denture base materials. J Adv Prosthodont. 2013; 2:153-60.

20. Nassar HI. Patient satisfaction of tooth supported overdentures utilizing ball attachments. Future Dental Journal. 2016;2:70-3.

21. Abdel-Bary SKH, Ali NH. Infuence of tooth-implant supported telescopic overdentures with cervical clearance on supporting structures of unilateral distal extension ridge. Egypt Dent J .2020; 1:485-94.

22. Alnafisah AM, Mahmoud MR. Tooth Supported Overdenture as an Amazing Solution for the Patient: A Case
Report. International Journal of Dental Sciences and Research. 2019; 1:21-4.

23. Shah FK, Gebreel A, Habib AA, Porwal A. Comparison of immediate complete denture, tooth and implant-supported overdenture on vertical dimension and muscle activity. J Adv Prosthodont. 2012; 2:61-71.

24. Kohli S, Bhatia S. Polyamides in dentistry. Int J Sci Study. 2013;1:20-5.

25. Elsaih EAE. Effect of different mandibular prosthesis on anterior maxillary ridge resorption (retrospective study). Dental journal. 2015; 131):138. 